Rahiman et al., Afr J Tradit Complement Altern Med. (2013) 10(1):124-127

http://dx.doi.org/10.4314/ajtcam.v10i1.16

\title{
VARIATION OF ANTIOXIDANT ACTIVITY AND PHENOLIC CONTENT OF SOME COMMON HOME REMEDIES WITH STORAGE TIME
}

\author{
Shaik Rahiman ${ }^{1}$, Bilal Ahmad Tantry ${ }^{2}$, Avneesh Kumar ${ }^{3}$ \\ ${ }^{1}$ Department of Biochemistry, College of Medicine, Al Jouf University, Saudi Arabia. ${ }^{2}$ Department of \\ Microbiology, College of Medicine, Al Jouf University, Sakaka, Al Jouf, P.O box 2014, Postal code \\ 75471, Kingdom of Saudi Arabia. ${ }^{3}$ Department of Microbiology, Institute of Applied Medicine and \\ Research, Ch. Charan Singh University, India.
}

*Email: rahimhi@gmail.com

\begin{abstract}
The variation of antioxidant activity and total phenolic content of some plants commonly used as home remedies were screened on the basis of air drying time of (short term and long term air) the dried plant Ocimum sanctum (leaf), Cucumis sativus (Seed), and ethanolic extracts of Capsicum frutescens (Seed) and Coriandrum sativum (Seed). Antioxidant activities and total phenolic content values were estimated using DPPH reagent and Folin Ciocalteu reagent methods respectively. The antioxidant activity in short term air dried Ocimum sanctum plant methanol extract $\left(\mathrm{IC}_{50}=0.03 \pm 0.01 \mathrm{mg} / \mathrm{l}\right)$ was the highest among the other plant extracts. However, Coriandrum sativum plant ethanol extract produced higher phenolic content (70.24 $\pm 3.4 / 66.57 \pm 4$.1 $\mathrm{mg} / \mathrm{g}$ ) than other plant extracts. It was found that there was no correlation between antioxidant and phenolic content of these plant extracts.
\end{abstract}

Key words: Natural antioxidants, Time factor, DPPH, short term air dried, long term air dried.

\section{Introduction}

Antioxidants help organisms deal with oxidative stress caused by free radical damage. Free radicals are chemical species, which contain one or more unpaired electrons due to which they are highly unstable and cause damage to other molecules by extracting electrons from them in order to attain stability. It has been established that oxidative stress is among the major causative factors in induction of many chronic and degenerative diseases including atherosclerosis, ischemic heart disease, ageing, diabetes mellitus, cancer, immune suppression, neurodegenerative diseases and others (Youngk and Woodside 2001).

There is an increasing interest in natural antioxidants, namely phenols, present in medicinal and dietary plants, that might help prevent oxidative damage (Gardner et al., 2000) and Youdim et al., ( 1994). The administration of an antioxidant source comprising of multiple components could offer protection against cancer and combat oxidative stress -induced physiological malfunctions (Ningappam et al., 2007). In situations of increased free radical generation, the reinforcement of endogenous antioxidants via intake of dietary antioxidants may be of particular importance in attenuating the cumulative effects of oxidatively damaged molecules. Therefore, the studies of possible new sources of antioxidants have become important in the last few years. The new sources of the antioxidants could be used for direct consumption or for the production of food supplements which could be used for enriching foods with the aim of increasing their nutritional value. Medicinal plants used in the traditional medicine and healing are one of these sources of antioxidants. In many countries, screening studies were carried out for the comparison of antioxidant activities of medicinal plants typical for the respective country (Chanwitheesuk et al., (2005), Ivanova et al., (2005), Katalinic et al., (2006) and Proestos et al., (2006). From ancient times, people have developed interest towards use of home remedies for the treatment of several kinds of diseases. It is highly appreciable that these remedies have no side effects and are absolutely inexpensive. Home remedy treatment deals with day-to-day problems, like cough and cold, headache, vomiting, stomach upset etc. Home remedy treatment makes use of things bestowed on us by nature like fruits, vegetables, herbs etc.

Ocimum sanctum (Tulsi), Cucumis sativus (Cucumber), Capsicum frutescens (Red chilly) and Coriandrum sativum (Coriandrum) have been widely used in traditional medicine in India as spice or herb for a long time. Among these, Ocimum sanctum commonly known as holy basil is a herbaceous sacred plant found throughout India. Indian Materia Medica describes the use of the plant in a variety of ailments. In Indian mythology, this plant is considered to extirpate all sins and purify the body when touched. It is often grown outside dwellings and worshipped daily. It is said to have mystical powers of protection from death, disease and misfortune (Williamson, 2002).

The purpose of the present study is to investigate the variation in antioxidant activity and phenolic content of short term air dried (immediately after air drying) and long term air dried ( Two months after air drying) plant extracts of some commonly used home remedies. Bearing in mind that very little information is available about the effect of time factor on antioxidant activities, the present investigation was conducted to study the change in the antioxidant activity of plants due to ageing of some air dried plant materials of Ocimum sanctum, Cucumis sativus, Capsicum frutescens and Coriandrum sativum. 


\section{Rahiman et al., Afr J Tradit Complement Altern Med. (2013) 10(1):124-127 http://dx.doi.org/10.4314/ajtcam.v10i1.16}

\section{Materials and Methods \\ Plant materials}

Four medicinal plant samples Ocimum sanctum (Lamiaceae), Cucumis sativus. (Cucurbitaceae), Capsicum frutescens (Solanaceae ) and Coriandrum sativum (Apiaceae) were collected from local vegetable plant nursery and seed market in Pamur, Andhra Pradesh province , INDIA. during 2010. All the plant materials were authenticated by a taxonomist. The plant materials presented in Table 1 were air-dried in a shed at room temperature $\left(26^{\circ} \mathrm{C}\right)$ for 2 weeks, after which these were ground to uniform powder.

\section{Chemical reagents}

The chemical reagents namely 2,2-diphenyl-1-picrylhydrazyl [DPPH], sodium carbonate[ $\mathrm{Na}_{2} \mathrm{CO}_{3}$, 3,4,5-Trihydroxybenzoic acid [gallic acid] and Folin-Ciocalteu`s phenol reagent, were purchased from Sigma-Aldrich Co.(USA). All other chemicals and solvents were of analytical grade

\section{Methanol extraction}

20 g each of powdered plant material (Ocimum sanctum and Cucumis sativus) was soaked in $150 \mathrm{ml}$ of methanol seperately at room temperature overnight. The solvents were decanted and residues macerated for two more days with the same solvent. The pooled solvents were combined and filtered. The filtrates were concentrated under reduced pressure at $40^{\circ} \mathrm{C}$ and yields of extract collected.

\section{Ethanol extraction}

The dried and powdered seeds (Capsicum frutescens and Coriandrum sativum) (20 g each) were extracted with 90\% ethanol for $48 \mathrm{hr}$. The extracts were filtered and concentrated under reduced pressure at $40^{\circ} \mathrm{C}$.

\section{Methods}

The study was conducted in two phases of 2 months interval. First the plant materials were screened for the antioxidant activity and total phenol content immediately after air drying the plant material. The second phase was conducted on same plant materials after two months of drying the plant materials. The methodologies used for both the phases of study were same, except for the time factor.

\section{Antioxidant activity (DPPH free radical scavenging activity) determination}

The antioxidant activity of the plant extracts was examined on the basis of the scavenging effect on the stable DPPH free radical activity (Braca et al., 2002). Ethanolic solution of DPPH $(0.05 \mathrm{mM})(300 \mu \mathrm{l})$ was added to $40 \mu \mathrm{l}$ of extract solution with different concentrations $(0.02-2 \mathrm{mg} / \mathrm{ml})$. DPPH solution was freshly prepared and kept in the dark at $4^{\circ} \mathrm{C} .2 .7 \mathrm{ml}$ of ethanol (96\%) was added and the mixture was shaken vigorously. The mixture was left to stand for $5 \mathrm{~min}$ and absorbance was measured spectrophotometrically at $517 \mathrm{~nm}$. Ethanol was used to set the absorbance zero. A blank sample containing the same amount of ethanol and DPPH was also prepared. All determinations were performed in triplicate. The radical scavenging activities of the tested samples, expressed as percentage of inhibition were calculated according to the following equation (Yen, and Duh 1994).

Percent (\%) inhibition of DPPH activity $=\left[\left(\mathrm{A}_{\mathrm{B}}-\mathrm{A}_{\mathrm{A}}\right) / \mathrm{A}_{\mathrm{B}}\right] \times 100$

where $A_{A}$ and $A_{B}$ are the absorbance values of the test and of the blank sample, respectively

\section{Determination of total phenol content}

Total phenol contents were estimated using Folin Ciocalteu reagent method (McDonald et al., (2001). A dilute extract of each plant extract $(0.5 \mathrm{ml}$ of 1:10 g/ml) or gallic acid used as standard was mixed with Folin Ciocalteu reagent (5 ml, 1:10 diluted with distilled water) and aqueous $\mathrm{Na} 2 \mathrm{CO} 3(4 \mathrm{ml}, 1 \mathrm{M})$. The mixture was allowed to stand for 10 min and the absorbance was measured by colorimetry at $765 \mathrm{~nm}$. The standard curve was prepared using $0,50,100,150,200,250 \mathrm{mg} / \mathrm{l} \mathrm{solutions}$ of gallic acid in methanol: water $(50: 50, \mathrm{v} / \mathrm{v})$. Total phenol contents were expressed in terms of gallic acid equivalent (mg/g of dry mass), which was used as the reference compound.

\section{Statistical analysis}

All the tests were conducted in triplicates. The data of all the parameters were statistically analyzed and expressed as mean \pm S.D with the aid of SPSS 17.0 Windows version. Analysis of Variance (ANOVA) was employed to express the significance of difference between results with p-values set at 0.05 . 
Rahiman et al., Afr J Tradit Complement Altern Med. (2013) 10(1):124-127

http://dx.doi.org/10.4314/ajtcam.v10i1.16

\section{Result and Discussion}

Spices and herbs have been used for thousands of centuries by many cultures to enhance the flavor and aroma of foods. Scientific experiments since the late $19^{\text {th }}$ century have documented the antioxidant properties of some spices, herbs, and their components (Bajpai et al., 2005). India is one of the richest countries in the world as regards genetic resources of medicinal plants. India has about 45, 000 plant species and among them, several thousands have been claimed to possess medicinal properties. In our system of medicine, Ayurveda, Sidha and Unani use over 2000 medicinal plants of which Ayurveda uses 700, Sidha, 600 and Unani, 700 medicinal plants (Vijayakumar et al., 2009).

Table 1: List of the plants and part of the plant extract used in this study

\begin{tabular}{|c|c|c|}
\hline Scientific names of plant under investigation & Family name & $\begin{array}{c}\text { Part of the plant } \\
\text { investigated }\end{array}$ \\
\hline Ocimum sanctum L & Lamiaceae & Leaf \\
\hline Cucumis sativus L. & Cucurbitaceae & Seed \\
\hline Capsicum frutescens & Solanaceae & Seed \\
\hline Coriandrum sativum & Apiaceae & Seed \\
\hline
\end{tabular}

Table 2: Comparison between phenolic content of short and long air dried plant extracts

\begin{tabular}{|c|c|c|c|}
\hline \multirow[b]{2}{*}{ Plant } & \multirow{2}{*}{ Extract type } & Short term dried sample & Long term dried sample \\
\hline & & Total phenol (mg/g) Mean \pm SD) & Total phenol (mg/g) Mean \pm SD) \\
\hline Ocimum sanctum L & Methanol & $48.93 \pm 2.1$ & $47.88 \pm 3.4$ \\
\hline Cucumis sativus L. & Methanol & $27.5 \pm 1.6$ & $26 \pm 2.6$ \\
\hline Capsicum frutescens & Ethanol & $16.22 \pm 1.1$ & $15.57 \pm 1.8$ \\
\hline Coriandrum sativum & Ethanol & $70.24 \pm 3.4$ & $66.57 \pm 4.1$ \\
\hline
\end{tabular}

$* \mathrm{P}<0.05$ is statistically significance

IC50: half inhibitory concentration

Table 3: Variation of antioxidant activity of short and long air dried plant extracts

\begin{tabular}{|l|c|c|c|}
\hline \multirow{2}{*}{ Plant } & \multirow{2}{*}{ Extract type } & Short term dried sample & Long term dried sample \\
\cline { 3 - 4 } & & $\begin{array}{c}\text { IC50 }(\mathrm{mg} / \mathrm{l}) \\
(\mathrm{Mean} \pm \mathrm{SD})\end{array}$ & $\begin{array}{c}\text { IC50 }(\mathrm{mg} / \mathrm{l}) \\
\text { Mean } \pm \text { SD) }\end{array}$ \\
\hline Ocimum sanctum L & Methanol & $* 0.03 \pm 0.01$ & $* 0.05 \pm 0,01$ \\
\hline Cucumis sativus L. & Methanol & $0.07 \pm 0.01$ & $0.09 \pm 0.02$ \\
\hline Capsicum frutescens & Ethanol & $0.56 \pm 0.5$ & $0.57 \pm 0.3$ \\
\hline
\end{tabular}

In general, processing conditions and drying methods affect yield and the retention of antioxidant activity (Moure et al., 2001). The total phenolic content of plant is shown in Table 2. Coriandrum sativum plant ethanol extract gave considerably more phenolic content (70.24 $\pm 3.4 \mathrm{mg} / \mathrm{g}$ in short term air dried plant and $66.57 \pm 4.1 \mathrm{mg} / \mathrm{g}$ in long term air dried sample) than other plant extracts at both the stages of analysis. The phenolic contents were slightly higher in extracts of short term air dried plant materials than long term air dried plant extracts in all the plant materials. It is well-known that phenolic compounds contribute to quality and nutritional value in terms of modifying color, taste, aroma, and flavor and also in providing health beneficial effects. They also serve in plant defense mechanisms to counteract reactive oxygen species (ROS) in order to survive and prevent molecular damage and damage by microorganisms, insects, and herbivores (Vaya et al., 1997). 
Rahiman et al., Afr J Tradit Complement Altern Med. (2013) 10(1):124-127

http://dx.doi.org/10.4314/ajtcam.v10i1.16

The antioxidant activities by DPPH free radical scavenging activity have been shown in Table 3 . The highest antioxidant activity was observed in Ocimum sanctum plant methanol extract $\left(\mathrm{IC}_{50}=0.03 \pm 0.01 \mathrm{mg} / \mathrm{l}\right)$ than other plant extracts. In contrast, Capsicum frutescens gave the lowest activity. Although some studies have demonstrated a correlation between phenolic content and antioxidant capacity (Yang et al., 2002), however there was no correlation between total phenolic content and antioxidant activity of the studied plant extracts in the present investigation. Coriandrum sativum plant ethanol extract gave higher phenolic content $(70.24 \pm 3.4 / 66.57 \pm 4.1 \mathrm{mg} / \mathrm{g})$ than other plant extracts, whereas Ocimum sanctum gave the highest antioxidant activity than other plant extracts. This is an indicated that there is no correlation between phenolic content and antioxidant activity of the studied home remedies. Bajpai et al.(2005), had also reported no correlation between total phenolic content and antioxidant capacities of a number of medicinal plant extracts. This no correlation between total phenolic content and antioxidant capacity in our plant samples may be due to the presence of the following factors: the antioxidant capacity observed may not be solely due to the phenolic contents, but could possibly be due to the presence of some other phytochemicals such as ascorbic acid, tocopherol and pigments as well as the synergistic effects among them, which also contribute to the total antioxidant capacity. On the other hand, total phenolic content determined according to the Folin- Ciocalteu method is not an absolute measurement of the amount of phenolic materials. Different types of phenolic compounds have different antioxidant activities, which is dependent on their structure. The extracts possibly contain different type of phenolic compounds, which have different antioxidant capacities.

\section{Conclusion}

Based on these results, it may be concluded that the selected home remedy plant materials are good sources of antioxidants and the effect of time duration on antioxidant activities and phenolic contents did not show significant variation.

\section{References}

1. Bajpai, M. Pande, A. Tewari, S.K. and Prakash, D. (2005). Phenolic contents and antioxidant activity of some food and medicinal plants. International Journal of Food Sciences and Nutrition. 2005;56(4): 287-291.

2. Braca, A. Sortino, C. Politi, M. (2002). Antioxidant activity of flavonoids from Licania licaniaeflora. J. Ethnopharmacol. 2002;79: 379-381.

3. Chanwitheesuk, A. Teerawutgulrag, A. Rakariyatham, N. (2005). Screening of antioxidant activity and antioxidant compounds of some edible plants of Thailand. Food Chemistry. 2005;92: 491-497

4. Gardner, P.T. White, T.A.C. McPhail, D.B. Duthie, G.G. (2006). The relative contributions of vitamin C, carotenoids and phenolics to the antioxidant potential of fruit juices. Food Chem. 2000;68: 471-474.

5. Ivanova, D. Gerova, D. Chervenkov, T. Yankova, T. (2005). Polyphenols and antioxidant capacity of Bulgarian medicinal plants. J.Ethnopharmacol. 2005; 96: 145-150.

6. Katalinic, V. Milos, M. Kulisic, T. Jukic, M. (2006). Screening of 70 medicinal plant extracts for antioxidant capacity and total phenols. Food Chem . 2006;94: 550-557.

7. McDonald, S. Prenzler, P.D. Autolovich, M. Robards, K. (2001). Phenolic content and antioxidant activity of olive extracts. Food Chem. 2001; 73: 73- 84.

8. Moure, A.J.M. Cruz, D. Franco, J.M. Dominguez, J. Sineiro, H. Dominguez, M. J. Nufiez and J. C. Parajo. (2001). Natural antioxidants from residual sources. Food Chem. 2001;72: 145-171.

9. Ningappam, M.B. Ramadas Dinesha. Leela Srinivas (2007). Antioxidant and free radical Scavenging activities of polyphenol-enriched curry leaf (Murraya koenigii L.) extracts. Food chem. 2007; 106: 720-728.

10. Proestos, C. Boziaris, I.S. Nychas, G.J.E. Komaitis, M. (2006). Analysis of flavonoids and phenolic acids in Greek aromatic plants: Investigation of their antioxidant capacity and antimicrobial activity. Food Chem. 2006;95: 664-671.

11. Vaya, J. Belinky, P.A and Aviram, M. (1997). Antioxidant constituents from licorice roots: Isolation, structure elucidation and antioxidative capacity toward LDL oxidation. Free Radical. Biol. Med. 1997;23(2): 302-313.

12. Vijayakumar, R. Chang-Xing, Z. Rengasamy, G. Abdul Jaleel, C. (2009). Non-enzymatic and enzymatic antioxidant variations in tender andmature leaves of Strychnos nux-vomica L. (Family: Loganiaceae). C.R Biologies.;332: 52-57.

13. Williamson, E.M. 2002. .Major herbs of Ayurveda. : Churchill Livingstone, London.

14. Yang, J.H. Lin, H.C. Mau, J.L. (2002). Antioxidant properties of several commercial mushrooms. Food Chem. 77:229235.

15. Yen, G.C. Duh, P.D. (1994). Scavenging effect of methanolic extracts of peanut hulls on free-radical and active oxygen species. J. Agric. Food Chem.42: 629-632.

16. Youdim, K.A. Spencer, J.P. Schroeter, H. and Rice-Evans, C. (1994). Dietary flavonoids as potential neuroprotectants. Biol. Chem. 2002;383:503-519.

17. Youngk I.S. Woodside, J.V. (2001). Antioxidants in health and disease. J.Clin. Pathol.;54: 176-186. 